\title{
The laboratory in the investigation of andropause: The contribution of hormonal measures to andropause diagnosis
}

\author{
Gilles Brisson PhD
}

$G$ Brisson. The laboratory in the investigation of andropause: The contribution of hormonal measures to andropause diagnosis. J Sex Reprod Med 2001;1(2):78-80.

Bioavailable testosterone assay constitutes a major improvement in clinical laboratory practice compared with the classic total testosterone assay for the identification of patients with partial androgen deficiency. It is also clear that clinical laboratories are not faced with obvious markers of primary hypogonadism but have to contribute to identifying a more subtle hypogonadal condition that does not involve testosterone uniquely; it probably involves a more complex endocrine condition with multiple components. In the near future, other markers may appear that may improve the diagnosis and treatment of men with partial androgen and other deficiencies.

Key Words: Bioavailable testosterone; Hypogonadism; Luteinizing hormone; Sex hormone-binding globulin; Reference range

\section{Le rôle des laboratoires dans l'exploration de l'andropause : la place de la mesure du taux d'hormone dans le diagnostic de l'andropause}

RÉSUMÉ : Le dosage de la testostérone biodisponible constitue un pas important en laboratoire clinique par rapport au dosage classique de la testostérone totale pour dépister les patients atteints d'un déficit partiel en androgènes. Par ailleurs, il ne fait aucun doute que les laboratoires cliniques ne se trouvent pas devant des marqueurs clairs d'hypogonadisme primaire mais qu'ils ont un rôle à jouer dans l'identification d'une affection hypogonadique subtile qui ne se limite pas à la testostérone; il s'agit là sans doute d'un trouble endocrinien, fort complexe, qui comporte une foule de manifestations. Dans un proche avenir, l'arrivée d'autres marqueurs pourrait faciliter la pose du diagnostic de déficit partiel en androgènes (ou d'autres substances) et son traitement.
$\mathrm{C}$ linical biochemists are responsible for providing laboratory services (to establish or develop new diagnostic tools) to support physicians in clinical care. Andropause is an emerging entity in laboratory medicine and has attracted considerable interest in the medical literature. It is a complex clinical condition for which it is difficult to establish a final and clear diagnosis.

As with many others diseases, there is no specific biochemical marker of andropause. However, it is recognized that there is a gradual decline in blood testosterone with aging and that a partial androgen deficiency may appear, even in apparently healthy men. Studies (1) have shown that from the ages of 40 to 70 years, there is a gradual decrease of $1.2 \% /$ year of free and non sex hormone-binding globulin (SHBG)-bound testosterone levels, also called bioavailable testosterone.

At the same time, a gradual increase in the SHBG level has been observed to enhance the binding of circulating 
testosterone in the blood and reduce the clearance of testosterone. A decrease in the pulse luteinizing hormone (LH) at the pituitary level is noted with the aging process.

It is obvious that laboratory analyses can significantly support the clinician in the investigation of andropause. Clinical biochemists must contribute to the diagnosis of andropause in patients by establishing a close relationship with clinicians interested in andropause, and by providing an appropritate analytical profile that will give an overall evaluation of the health of a patient and, if necessary, offer new diagnostic tools to support a medical diagnosis.

\section{BASIC BIOCHEMICAL PROFILE}

After the physical examination and a review of the patients' signs and symptoms, it is suggested that physicians request a basal biochemical profile that gives an overview of the general health of the patient. Patients with a chronic pathology should first be treated for their primary illness. Drug and alcohol consumption, and medications should be documented and considered in the clinical evaluation. The profile is preferably obtained fasting between 08:00 and 10:00 and should include the following parameters:

- glycemia;

- creatinine;

- alamine transferase;

- total protein and albumin;

- a lipid profile with high density lipoprotein cholesterol; and

- iron and transferrin or total iron-binding capacity.

The above parameters identify a diabetic patient or any risk factor related to the lipid profile, and will give insight into liver and renal function. Anemia must also be excluded, and hemoglobin and hematocrit measurements should be ordered before treatment begins. A rectal examination and prostate-specific androgen testing are prerequisites for prostate evaluation. Finally, a hormonal profile that contributes to the diagnosis of andropause should also be requested and should include an analysis of the following hormones.

\section{THYROID PROFILE}

A test for the levels of thyroid-stimulating hormone (TSH) with free thyroxine, if necessary, must be obtained to determine the patient's thyroid status. The reference range for TSH level is well establish in clinical laboratories. However, if the TSH value is over $4 \mathrm{mU} / \mathrm{L}$ subclinical hypothyroidism should be suspected in the andropausal patient, and followup should be arranged.

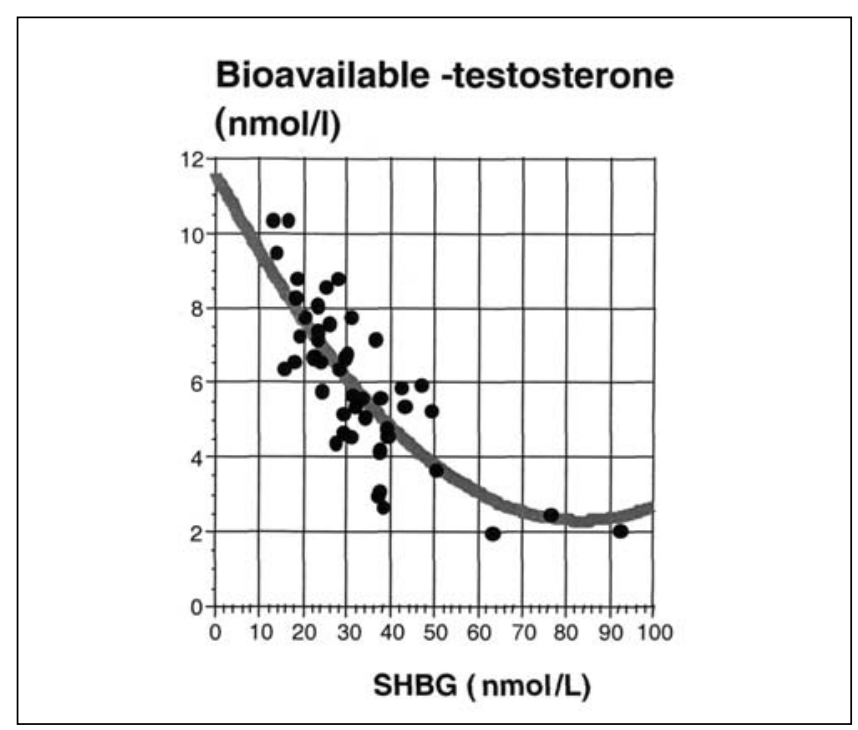

Figure 1) Relation of bioavailable testosterone to sex hormone-binding globulin (SHBG) at a total testosterone level of $14 \mathrm{nmol} / \mathrm{L}$

\section{INSULINEMIA}

An analysis for insulinemia using fasting glucose concentrations is suggested to document insulin resistance, mainly if the patient presents with overt obesity and it is linked to a risk of diabetes.

\section{PROLACTIN}

An analysis of prolactin levels should be requested because of their influence on testosterone production and metabolism, and their action at the hypothalamo-pituitary level. If the prolactin level is above $100 \mathrm{ng} / \mathrm{mL}$, a pituitary adenoma should be suspected; a lower level may signify that the patient is taking medications or has idiopathic hyperprolactinemia. If a prolactin level between 20 to $35 \mathrm{ng} / \mathrm{mL}$ is observed, the basal prolactin level should be verified by a repeat analysis of blood samples. It is appropriate to obtain blood samples at time 0,20 and 40 min to eliminate the influence of stress on the release of prolactin.

\section{LUTEINIZING HORMONE}

It is known that there is a gradual decrease in the sensitivity of the hypothalamo-pituitary axis to the negative feedback action of androgen with aging. The LH level will inform on the integrity of the axis at the pituitary level, the hypogonadism status (primary or secondary) or the androgen resistance observed. However, it is important that the laboratory re-evaluate the reference range for men who are 50 years of age and older to clearly define their LH level.

In the author's experience, the LH values observed in men aged 40 to 50 years are significantly lower than the reference range of 1 to $10 \mathrm{U} / \mathrm{L}$ that is usually reported for men by diagnostic laboratories.

\section{ANDROGEN PROFILE}

Recently, at its 82nd annual meeting, the Endocrine Society (2) emphasized the importance of establishing an 
TABLE 1

Reference range of testosterone fractions in men aged 40 to 49 years

\begin{tabular}{lcc}
\hline & \multicolumn{2}{c}{ Percentile } \\
& $\mathbf{5 \%}$ & $\mathbf{9 5 \%}$ \\
\hline Total testosterone (nmol/L) & 8.0 & 30 \\
Bioavailable testosterone (nmol/L) & 3.5 & 12 \\
Sex hormone-binding globulin (nmol/L) & 15.0 & 60 \\
\hline
\end{tabular}

appropriate diagnosis of hypogonadism (low testosterone levels) in men.

It is obvious that testosterone measurement is required to establish a presumptive diagnosis of hypogonadism. Recently, Kandeel et al (3) presented an algorithm that allowed bioavailable testosterone measurement. It is increasingly recommended that the bioavailable fraction of testosterone, which corresponds better to the testosterone concentration acting at the tissue level, be measured. The author also realizes that total testosterone levels do not identify partial androgen deficiency. The SHBG level or the binding proteins that link testosterone provide better insight into the level of bioavailable testosterone, as shown in Figure 1. In patients with normal testosterone levels but elevated SHBG and albumin levels, an abnormal level of bioavailable testosterone is observed. This observation is also true for all testosterone levels found in a patient.

\section{REFERENCE RANGE FOR BIOAVAILABLE TESTOSTERONE}

Many authors have reported their own reference range for bioavailable testosterone. Tremblay (4), in a recent paper, summarized the reference range of the lower value reported by many authors for the diagnosis of partial hypogonadism.

Various approaches, which are not officially recognized, can be used by clinical laboratories to measure precisely (5) or give an estimation (6) of the free or bioavailable testosterone fraction using the total testosterone and SHBG levels in serum.

However, there is no commercial kit for measuringbioavailable testosterone, and the reference or the equilibrium dialysis methods used to measure the free testosterone fraction cannot be used on a routine basis by clinical laboratories.

The bioavailable method that is measured following ammonium sulfate precipitation of SHBG is quite difficult, and requires excellent technical skill and special standardization to avoid technical bias and unacceptable imprecision. On the other hand, the calculation method is based on two independent, imprecise methods that assume that SHBG and albumin are single homogeneous proteins with a single binding property.

It is obvious that both bioavailable and calculed free testosterone methods show technical weakness. However, these methods show acceptable precision that is better than that of measuring total testosterone.

There is no concensus on the criteria that define the reference range of bioavailable testosterone for the diagnosis of andropause. However, the majority of authors agree that a level of bioavailable testosterone between 2.5 and $3.5 \mathrm{nmol} / \mathrm{L}$ is probably the lower end of the normal range to be considered for a diagnosis of andropause.

The usual procedure (mean $\pm 2 \mathrm{SD}$ of a reference age group) applied by clinical laboratoies to define a normal range probably cannot be applied to identify andropause.

For this reason, it is suggested that a level of between the fifth and 95th percentiles of bioavailable testosterone observed in men aged 40 to 49 years should be used as a reference range because, usually, these men do not show symptoms of andropause. Table 1 shows the local reference range observed for bioavailable testosterone per age group. These values are comparable with those reported in other studies (7).

\section{CONCLUSIONS}

It is obvious that bioavailable testosterone assays constitute a major improvement in clinical laboratory practice compared with the classic total testosterone assay for the identification of patients with partial androgen deficiency. It is also clear that clinical laboratories are not faced with obvious markers of primary hypogonadism but have to contribute to identifying a more subtle hypogonadal condition that does not involve testosterone uniquely; it probably involves a more complex endocrine condition with multiple components. In the near future, other markers may appear that may improve the diagnosis and treatment of men with partial androgen and other deficiencies.

\section{REFERENCES}

1. Gray A, Feldman HA, McKinlay JB, Longcope C. Age, disease, and changing sex hormone levels in middle-aged men: results of the Massachusetts Male Aging Study. J Clin Endocrinol Metab 1991;3:1016-25.

2. Swerdloff R, Bhasin S, Blackman MR, et al. Consensus Session from the 1st Annual Andropause Consensus 2000 Meeting. Satellite Symposium of the 82nd annual meeting of the Endocrine Society. Toronto, June 2000.

3. Kandeel FR, Koussa VK, Swerdloff RS. Male sexual function and its disorders: physiology, pathophysiology, clinical investigation, and treatment. Endocr Rev 2001;22:342-88.

4. Tremblay RR. A new diagnostic tool for andropause diaganosis. Le clinicien February 2001;158-68.

5. Tremblay RR, Masse J. Usefulness and limitation of bioavailable testosterone in assessment of androgenicity during the process of aging in men. Aging Male 1999;1:16-21.

6. Vermeulen A, Verdonck L, Kaufmen JM. A critical evaluation of simple methods for the estimation of free testosterone in serum. J Clin Endocrinol Metab 1999;84:3666-72.

7. Ferrini RL, Barret-Connor E. Sex hormones and age: a crosssectional study of testosterone, estradiol and their bioavailable fractions in community-dwelling men. Am J Epidemiol 1998;14:750-4. 